\title{
Selenium: a vital element in soil-pant-animal/human continuum.
}

\author{
Uttam Kumar Saha* \\ Feed and Environmental Water Laboratory, The University of Georgia, GA, USA
}

Accepted August 12, 2017

In 1817, Berzelius, a Swedish chemist discovered Selenium (Se) as one of the 103 chemical elements [1]. The animal nutritionists are in consensus that essentiality of Se in animal physiology and nutrition was first reported by Schwarz and Foltz [2]. However, Leo [3] described that the experimental evidence showing the importance of Se in animal diets was published as early as 1941 by Poley et al. [4]. In that paper, Poley et al. [4] described their remarkable observation of faster growth of chicks when they consumed a diet containing $2 \mathrm{ppm}$ Se composed of an appropriate combination of Se-rich grains corn, barley and wheat grown in Se-rich soils of South Dakota. Despite all these observations, a definitive evidence of essential biological role of Se became available as late as 1973, when Glutathione Peroxidase (GSHpx) (which are 'selenoproteins') was first identified as an enzyme system that contain Se as an integral structural component $[5,6]$. Mehdi et al. [7] described eight different forms of GSHpx with some common features but with unique modes and sites of action and different chemical structures. Besides GSHpx, scientists have identified several other kinds of selenoproteins or enzymes containing Se as a structural component such as deiodinases (thyroid hormones), thioredoxin reductases, selenophosphate synthatase, selenoprotein $\mathrm{P}$, selenoprotein $\mathrm{W}$, and few others $[8,9]$. The total number selenoproteins identified so far could be as many as 30 or may be even few more, but there are 25 that exist in humans and mammals [7,10]. Notably, the Se-containing GSHpx enzyme system plays an extremely vital role in animal and human physiology and health. Because of this, Se is now recognized as a unique essential micronutrient in animal and human diets. However, Se intake exceeding its tolerance limit exerts toxic effects human and animal health. Due this doubleedged role of Se, as an essential nutrient and a toxic constituent, proper attention must be paid to ensure that concentration of Se animal and human diets is maintained within its beneficial range [11]. Alexander et al. have described chronic poisoning of livestock and humans due to long-term exposure to $\mathrm{Se}$ in the areas with high levels of soil Se [12]. The availability of Se in the soil and consequently to food and feed crops could greatly benefit or harms animal/human nutrition and health.

Body metabolizes carbohydrates, fats, and proteins of foods or feeds by an oxidation process. Such oxidative metabolic activity on food and feed produces carbon dioxide, water, and energy to be utilized for various body functions like work, weight gain, milk production, etc. However, it is undesirable and harmful if body's structural (e.g., cell membranes) and functional (e.g., enzymes and intracellular substances) components get oxidized concomitantly. A simple analogy is that although a car burns gasoline to create its required driving force to travel, an adequate protection is in place so that the its own components are not burnt during this process [13]. Thus, there is a clear need for a defense system to prevent from oxidative damage in animal/human body. The body naturally protects itself from such oxidative damage by an antioxidant defense mechanism or simply antioxidant activity [13].

A sequential reduction process on molecular oxygen generates water as the ultimate product. However, this process generates various Reactive Oxygen Species (ROS) in sequence as intermediate products. These intermediate ROS include superoxide anion (which is both ion and radical), peroxide (hydrogen peroxide; organic peroxides), and hydroxyl radical (the most reactive one). Besides, when body breaks down proteins, several Nitrogen Free Radicals (NFRs) are produced. As an example, during reaction of arginine (an amino acid) and oxygen to form citrulline (another amino acid), the NFR Nitric Oxide (NO) is produced. Nitric oxide can react with the superoxide $\left(\mathrm{O}_{2}^{-}\right)$anion forming peroxynitrite (ONOO-). Both nitric oxide and peroxynitrite can cause cell damage in different ways. The ROS and NFRs are known for their damaging oxidative effects on animal and human body, which must be destroyed. Otherwise, they can cause damages to proteins, lipids (fat), and nucleic acids (DNA and RNA) of the living cells. The unsaturated fatty acids, which are the major component of all cell membranes, are particularly susceptible to such oxidative damage. When ROS attacks unsaturated fatty acids, lipid hydroperoxides (organic peroxides) could be formed, which is very damaging. Mitochondrial, red blood, and gastrointestinal cell membranes are particularly susceptible to such damage [9].

Many selenoproteins are involved in maintaining oxidationreduction balance in cells by preventing the formation of ROS and NFR as well as scavenging them once they are formed [14]. The GSHpx family of selenoproteins (or enzymes) is particularly effective in these activities. Glutathione also prevents oxidative damage and ensure cell membrane integrity by catalyzing the reduction of the hydrogen peroxide and lipid hydroperoxides $[15,16]$. Such reduction process converts hydrogen peroxide to harmless water and lipid hydroperoxides to harmless lipid alcohols. Because Se is an integral component of GSHpx, the activity of GSHpx is highly dependent on the levels of bioactive forms of Se in the body. Selenium deficiency causes a remarkable depletion of the activity of GSHpx and other Se-dependent enzymes with a concomitant depletion of defense capacity against oxidative damage $[17,18]$. Rayman [1] described Se as important to many vital physiological functions in human and animal body because it is an integral component of various vital enzyme systems namely such as GSHpx, thioredoxin reductase, and thyroid hormone deiodinase families. Benstoem et al. [19] described a wide range of beneficial biological functions of $\mathrm{Se}$ dependent enzymes including thyroid hormone metabolism, 
antioxidant defense systems, the adaptive, acquired immune system, prevention of certain cancers, and normal functioning of the cardiovascular system. In addition, GSHpx and thioredoxin reductase play an important role in maintaining bone homeostasis and protecting against bone loss [20]. Selenium has also been shown to play an important role in the normal functioning of the cardiovascular system [19]. Various human health problems such as heart diseases, hypothyroidism, reduced male fertility, weakened immune system and enhanced susceptibility to infections and cancer have been linked to Se deficiency $[21,22]$. Other authors described muscular dystrophy and pain, inflammation of the muscles, fragile red blood cells, necrotic liver degeneration, hair or skin abnormal coloration, and exudative diathesis in many warm-blooded animals as symptoms of selenium deficiency [23,24].

Despite many vital beneficial role of Se, the ranges of beneficial and toxic levels of Se in both human and animal body are fairly close to each other [25]. Inorganic Se in animal and human body can also act as a proxidant when present in excessive amount [26]. Pro-oxidant activity, an antonym of antioxidant activity, is undesirable. Inorganic Se compounds such as sodium selenite, Se dioxide and diselenides have been shown to have such pro-oxidant activity of catalyzing the oxidation of beneficial thiols such as glutathione with a concomitant production of superoxide and other ROS [27]. Spallholz [27] also suggested that Se toxicity in cells could be an outcome of such catalytic reaction of inorganic Se with thiols in the primary glutathione producing organs, such as the liver.

Even though the essentiality of Se in animal and human nutrition has been unequivocally established, and it has also been found essential for bacteria as well as the green algae (Chlamydomonas reinhardt), it is not yet recognized as an essential nutrient for higher plants [28]. However, Se has been shown to have many beneficial effects on plant growth such as growth promoting effect, anti-oxidative effects, senescence delay, and reduced herbivory [13]. Tremendous growth promoting effects of Se (up to 2.8-fold higher biomass with Se) have been observed primarily in the Se hyperaccumulator plants [29]. Small amount of Se application also promoted growth to some extent in a number of non-hyperaccumulator species including ryegrass, lettuce, potato, and duckweed [30]. Nevertheless, there is ample evidence that Se can protect plants from biotic stresses. In both hyperaccumulator and non-hyperaccumulator species, Se protected the plants from a wide variety of herbivores, as well as from fungal infections [31]. Thus, fertilization with low doses of Se may promote plant growth to some extent and increase resistance to pests and other stresses in various food and feed crops, which has been remaining under-investigated.

Low Se levels in humans and animals have been associated with low Se levels in the soil because the soil is a source of Se for feed and food crops consumed by animals and humans [32]. There are huge variations Se contents for soils from different parts of the world with high Se in some US and Venezuela soils to low concentrations in the soils of Korea, some regions of China and some parts of Europe [33]. Wide differences in geology, soil, climatic factors, food and fodder from various parts of the world imply a high variability in their ability to provide selenium for dietary intake in humans and animals [34,35]. Many parts of the world such as Europe and Asia are characterized by Se deficiency in soils, crops, animals and humans. Deficiency of Se affects as many as 800 million people around the world [36]. In order to correct the deficiencies and meet the recommended daily intake requirements for Se, both animal and human diets could be supplemented either directly or via biofortification of forage, animal feed, food crops and food products. Both genetic and agronomical biofortification could be used to increase Se levels in feed and food crops to ensure that Se requirements of human and animal are met. Nevertheless, given the fact the window between Se deficiency and toxicity is relatively narrow, in case of biofortification with $\mathrm{Se}$, it is indispensable to carefully monitor the Se levels in the final food products, to avoid toxicity. Above all, a holistic vision in understanding the origin and impact of Se deficiencies in living systems should be used to correct the deficiencies and ensure adequate Se nutrition of animals and human population for optimum health. This is a vital multidisciplinary subject area merits further attention of the researchers and development professionals.

\section{References}

1. Rayman MP. The importance of selenium to human health. Lancet. 2000;356:233-41.

2. Schwarz K, Foltz CM. Selenium as an integral part of factor 3 against dietary necrotic liver degeneration. J Am Chem Soc. 1957;79:3392-3.

3. Leo SJ. History and importance of selenium for poultry. A. L. Moxon Honorary Lectures, Special Circular, Extension/ Research Bulletin, The Ohio State University. 1999;167-99.

4. Poley WE, Wilson WO, Moxon AL, et al. The effect of selenized grains on the rate of growth in chicks. Poult Sci. 1941;20:171.

5. Rotruck JT, Pope AL, Ganther HE et al. Selenium: Biochemical role as a component of glutathione peroxidase. Sci. 1973;59:588-90.

6. Hefnawy A, Tortora-Perez JL. The importance of selenium and the effects of its deficiency in animal health. Small Rumin Res. 2010;89:185-92.

7. Mehdi Y, Hornick J, Istasse L, et al. Selenium in the Environment, Metabolism and Involvement in Body Functions. Molecules. 2013;18:3292-311.

8. Kohrle J. The deiodinase family: Selenoenzymes regulating thyroid hormone availability and action. Cell Mol Life Sci. 2000;57:1853-63.

9. Behne D, Kyriakopulos A. Mammalian selenium containing proteins. Annu Rev Nutr. 2001;21:453-73.

10. Thomson CD. Selenium, in Benjamin caballero ed. encyclopedia of human nutrition ( $3^{\text {rd }}$ edn. $)$. Academic Press, Waltham. 2013;186-92.

11. Handa N, Bhardwaj R, Kaur H, et al. Selenium: An antioxidative protectant in plants under stress. In: Ahmad $\mathrm{P}$ (ed.) Plant Metal Interaction, Elsevier. 2016;179-207. 
12. Alexander JS, Gunnar N. Handbook on the toxicology of metals ( $4^{\text {th }}$ edn.). Academic Press, San Diego. pp: 1175-208.

13. Saha U, Fayiga A, Sonon L. Selenium in the soil-plant environment: a review. Int J Appl Agric Sci. 2017;3:1-18.

14. Zeng H, Cao JJ, Combs GF. Selenium in bone health: roles in antioxidant protection and cell proliferation. Nutr. 2013;5:97-110.

15. Hoekstra WG. Biochemical role of selenium. In: Hoekstra WG, Suttie JW, Ganther HE and Mertz W (eds.) Trace Element Metabolism in Animals, No. 2. University Park Press, Baltimore. 1974;61-77.

16. Wendel A. Glutathione peroxidase. In: Jakoby WB (ed.) Enzymatic Basis of Detoxification, Academic Press, New York. 1980;1:333-53.

17. Hornsby PJ, Pearson DW, Autor AP, et al. Selenium deficiency in cultured adrenocortical cells: Restoration of glutathione peroxidase and resistance to hydroperoxides on addition of selenium. J Cell Physiol. 1985;123:33-8.

18. Burk RF. Protection against free radical injury by selenoenzymes. Pharmacol Ther. 1990;45:383-85.

19. Benstoem C, Goetzenich A, Kraemer S, et al. Selenium and its supplementation in cardiovascular disease - what do we know? Nutr. 2015;7:3094-118.

20. Zhang Z, Zhang J, Xiao J. Selenoproteins and selenium status in bone physiology and pathology. Biochimica et Biophysica Acta. 2014;1840:3246-56.

21. Hatfield DL, Tsuji PA, Carlson BA, et al. Selenium and selenocysteine: roles in cancer, health, and development. Trends Biochem Sci. 2014;39:112-120.

22. Roman M, Jitaru P, Barbante C. Selenium biochemistry and its role for human health. Metallomics. 2014;6:25-54.

23. Riaz M, Mehmood KT. Selenium in human health and disease: A review. J Postgrad Med Inst. 2011;26:120-33.

24. Guo L, Lang M, Chandrasekar R, et al. Advances in the study of genetic enrichment of selenium in plants. Clon Transgen. 2014;3:121.

25. Li SJ, Li W, Hu X, et al. Soil selenium concentration and
Kashin-Beck disease prevalence in Tibet, China. Front. Environ Sci Eng China. 2009;3:62-8.

26. Hasanuzzaman M, Hossain MA, Fujita M. Selenium in higher plants: Physiological role, antioxidant metabolism and abiotic stress tolerance. J Plant Sci. 2010;5:354-75.

27. Spallholz JE. Free radical generation by selenium compounds and their prooxidant toxicity. Biomed Environ Sci. 1997;10:260-70.

28. Fu LH, Wang XF, Eyal Y, et al. A selenoprotein in the plant kingdom: Mass spectrometry confirms that an opal codon (UGA) encodes selenocysteine in Chlamydomonas reinhardtii glutathione peroxidase. $\mathrm{J}$ Biol Chem. 2002;277:25983-91.

29. Shrift A. Aspects of selenium metabolism in higher plants. Ann Rev Plant Physiol. 1969;20:475-94.

30. Hartikainen H. Biogeochemistry of selenium and its impact on food chain quality and human health. J Trace Elem Med Biol. 2005;18:309-18.

31. Quinn CF, Galeas ML, Freeman JL, et al. Selenium: Deterrence, toxicity, and adaptation. Integr Environ Assess Manag. 2007;3:460-62.

32. Alfthan G, Eurola M, Ekholm P, et al. Effects of nationwide addition of selenium to fertilizers on foods, and animal and human health in Finland: From deficiency to optimal selenium status of the population. J Trace Elem Med Biol. 2015;31:142-47.

33. Fordyce F. Selenium deficiency and toxicity in the environment. In: Selinus O (ed.) Essentials of medical geology, Elsevier. 2005;373-415.

34. Rayman MP. Food-chain selenium and human health: Emphasis on intake. Br J Nutr. 2008;100:254-68.

35. Johnson CC, Fordyce FM, Rayman MP. Symposium on Geographical and geological influences on nutrition: factors controlling the distribution of selenium in the environment and their impact on health and nutrition. Proc Nutr Soc. 2010;69:119-32.

36. Malagoli M, Schiavon M, Dall Acqua S, et al. Effects of selenium biofortification on crop nutritional quality. Front Plant Sci. 2015;6:280.

\section{*Correspondence to}

Uttam Kumar Saha

Feed and Environmental Water Laboratory

The University of Georgia

GA, USA 